\title{
Moments of Connection: Building Equitable Relationships Between Families and Educators Through Participatory Design Research
}

Journal of Family Diversity in Education, 2021/2022 Vol. 4, No. 2, pp. 141-159

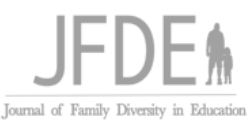

\author{
Paul J. Kuttner \\ University of Utah
}

Almaida Yanagui
Utah Community Advocate Network \& University of Utah

Gerardo R. López

Michigan State University

\author{
Anne Barton \\ University of Utah \\ Jennifer Mayer-Glenn \\ University of Utah
}

\begin{abstract}
Recent years have borne evidence of a resurgence of calls for schools to include families in school decision-making as part of a broader movement for equitable family-school partnerships; these partnerships require strong parent-teacher relationships characterized by mutual trust. However, such relationships are inevitably shaped by systems and histories related to racialization and power. This article explores how culturally and linguistically diverse families alongside teachers from the dominant school culture can begin building trusting relationships in spite of inequity. Its basis is an in-depth analysis of family-educator interactions in a participatory design-based research project in Salt Lake City, UT. We extract what we call moments of connection - moments when participants connected with one another despite the personal, historical, social, and institutional forces that so often divide them. We utilize these moments to suggest avenues for building trust, solidarity, and increasingly humanizing forms of engagement in our schools and communities.
\end{abstract}

Keywords: design research, co-design, site-based management, family engagement, family-school partnerships, political trust, relational trust, family leadership

\section{Corresponding Author:}

Paul J. Kuttner., Ed.D., Associate Director for Community Engaged Scholarship at University Neighborhood

Partners, The University of Utah, 1060 South 900 West, Salt Lake City, UT, 84104

Email: paul.kuttner@partners.utah.edu 
On a summer morning, 20 adults arrived at the Glendale-Mountain View Community Learning Campus in Salt Lake City, UT. They selected pastries and coffee from the counter and sat in four small groups around square tables; younger children were in the room next door for childcare. This gathering was unique in both its makeup and its goal. One half of the participants were parents of children in local schools, and the majority of these parents were Spanish-speaking residents from immigrant and migrant communities on the city's west side. The remainder of the participants were educators from various levels of the $\mathrm{K}-12$ system; the majority of these were White and and worked in west side schools while living outside of that area. These individuals and others had gathered 3 times over the course of a month to discuss how families and educators could better collaborate regarding shared decision-making at school sites.

They were engaged in redesigning a form of site-based school decision-making called School Community Council (SCC), a body legislated to include parents in the development of school improvement plans and the disbursement of state funds. Participants engaged not only as families and educators but also as coresearchers in a form of participatory design research called solidarity-driven codesign (Bang \& Vossoughi, 2016; Ishimaru et al., 2019) that aimed to reimagine SCCs as spaces for equitable family-school collaboration (FSC). Participants were asked to contribute to a collective act of critical imagination (Cartwright \& Noone, 2006; Greene, 2000) - to critique the SCC as it is and to imagine how it could be.

The push to include families in school decision-making has been revived in the past decade amid growing calls for more equitable forms of family engagement in which families and educators share power and view each other as partners (Christenson \& Reschly, 2010; Epstein et al., 2018; Hong, 2019; Ishimaru, 2019a; Khalifa, Gooden, \& Davis, 2016; Mapp, Carver, \& Lander, 2017). Collaboration requires strong, positive relationships between families and professional educators; these relationships must be characterized by mutual trust, understanding, openness, valuing of each other's assets, and shared power (Bryk \& Schneider, 2003; Clarke, Sheridan, \& Woods, 2010). Building such relationships between culturally and linguistically diverse (CLD) families and educators from the dominant school culture requires more than opportunities for families and educators to become acquainted with each other (Park \& Paulick, 2021). Such relationships are inevitably shaped by and must contend with the racial and social hierarchies of society, discourses that dehumanize and pathologize CLD families, and legitimate reasons that CLD communities distrust the schools that have harmed or failed them in the past (Lawrence-Lightfoot, 2003; Olivos, 2006; Vakil, de Royston, Nasir, \& Kirshner, 2016).

Consequently, the relevant que $\mathrm{nm}$ stions are as follows: How can equitable, power-sharing relationships between families and professional educators be intentionally built and maintained in a context of inequity? How can families and educators move from alienation to collaboration, distrust to partnership, and conflict to solidarity? Where are the openings, or aperturas (Ishimaru \& Bang, 2016), through which new kinds of relationships can be formed? These questions are at the core of the project we describe in this article. We comprise a community engagement professional, a community organizer, a critical scholar, a graduate student, and a lifelong public school educator. We are members of a design research team gathered around a shared commitment to family leadership in schools. In this article, we reflect on our first project together.

The primary goal of our project was to redesign SCCs to be spaces that foster collaborative, equitable relationships between families and educators. In addition, we utilized the design research process itself to explore and foster these relationships. As with other efforts to build equitable collaboration, we encountered challenges - some members were privileged and others were silenced, and social hierarchies asserted themselves within our circle. However, we also witnessed moments of understanding, empathy, learning, and collaboration. In this paper, we examine these moments what we call moments of connection - to mine them for their insights into how we may begin building 
the relational bridges through which equitable FSC thrives. Ultimately, we argue, these moments not only suggest opportunities to build trust but also offer a peek into developing increasingly humanizing forms of family engagement (Gallo, 2017) in our schools and communities.

\section{Shared Decision-Making, Family-School Collaboration, and Relational-Political Trust}

The past 60 years have seen several major initiatives to involve families in formal school decisionmaking processes, both in the US and abroad (Moradi, Hussin, \& Barzegar, 2012; Preston, 2009). Under names such as site-based management and shared governance, these efforts have produced different forms of community councils with various levels of decision-making power scattered across the schooling landscape. Proponents of these councils argue that they can fulfill families' rights to have a voice in their children's educations, make schools more accountable and responsive to communities, advance needed reforms, keep parents from exiting the public school system, and ultimately lead to better and more equitable schools (Malen \& Ogawa, 1988; Martell, 2008; Preston, 2009).

Research on such councils is mixed. Studies of Chicago's powerful local school councils offer evidence that well-functioning councils can effectively advocate for improved academic programming and facilities, increase families' involvement in schools, and build partnerships (Designs for Change, 2002). Councils with strong CLD family representation and necessary support are effective in building stronger understanding of community cultures among teachers while strengthening relationships between schools and CLD families (Marschall, 2006). However, while councils can work under certain conditions (Nygaard, 2010), they are often dominated by administrators and teachers, privilege middleclass White families who share backgrounds with school staff, involve parents largely in topics peripheral to teaching and learning, and do not contribute to changing fundamental school functions or power relationships (Anderson, 1998; Brown \& Hunter, 1998; Malen \& Ogawa, 1998). At worst, the discourse of participation becomes a way to control or co-opt parents from marginalized and racialized communities, deflect criticism from school leaders, and lead to rubber-stamping that legitimizes the status quo without changing inequitable distribution of resources and opportunities (Anderson, 1998; Brown \& Hunter, 1998; Malen \& Ogawa, 1998).

In recent years, a surge of calls has arisen demanding that schools move beyond traditional forms of parental involvement (e.g., volunteering in the office, attending parent-teacher conferences, or reading school newsletters) toward engaging, collaborating, and partnering in more equitable, reciprocal, and culturally responsive or sustaining ways regarding student learning and development (Christenson \& Reschly, 2010; Epstein et al., 2018; Henderson, Mapp, Johnson, \& Davies, 2007; Hong, 2019; Ishimaru, 2019a, 2019b; Khalifa, Gooden, \& Davis, 2016; Mapp, Carver, \& Lander, 2017). This includes efforts for schools to share power with families as leaders and decision makers (Hong, 2011; Warren, Mapp, \& Kuttner, 2015), recognizing the wealth of knowledge and assets that families provide (González, Moll, \& Amanti, 2006; López, 2001; López \& Vàzquez, 2006; Yosso, 2005) as well as the power of organized parents to promote educational justice and systemic change (Mediratta, McAlister, \& Shah, 2009; Warren, Mapp, \& the Community Organizing and School Reform Project, 2011).

Equitable FSC requires strong family-educator relationships that are rooted in mutual trust (Gallo, 2018; Ishimaru, 2019a). Addressing the challenges of partnership requires what Bryk and Schneider (2003) call relational trust, which is a vital lubricant for collaboration. Bryk and Schneider (2003) offer four considerations that, when present, foster trust: (a) respect, which includes authentically listening to another person and considering their perspectives; (b) personal regard, which is expressed through a proactive willingness to engage and be open; (c) competence, which is the sense that someone has 
the knowledge and skills to fulfill their role; and (d) personal integrity, which determines whether an individual does what they say they will do. In their review of multidisciplinary definitions of trust, Tschannen-Moran and Hoy (2000) provide a somewhat different but overlapping taxonomy of trust that includes willing vulnerability, benevolence, reliability, competence, honesty, and openness. Trust cannot be assumed or legislated, and the process of building trust is never complete. Rather, it must be constantly recreated and reinforced through repeated social interactions in which the parties demonstrate the above considerations (Bryk \& Schneider, 2003).

Trusting family-educator relationships are often lacking in schools. Relationships in many schools are characterized by mistrust on both sides, with educators tending to be less trusting of families than vice versa (Adams \& Christenson, 1998, 2000). This particular issue is present in a growing number of schools in which a majority White educator workforce teaches a student body from CLD communities, including bicultural and immigrant communities of Latinx background (Olivos, 2006). Social hierarchies in language, race, and culture as well as personal and community histories of harm and marginalization by schools influence every family-school interaction (Lawrence-Lightfoot, 2003). These disconnections are rooted in the racism, colonialism, and inequity that have been - and continue to be - fundamental to the structures of U.S. schooling (Race Forward, 2006; Warren, Mapp, \& the Community Organizing for Education Reform Project, 2011). Systemic injustices are replicated in the microcosm of schools, leading to a dominant ideology that views families of color and bicultural families through a deficit lens - as problems rather than solutions to educational inequities (Delgado Gaitan, 2012; Olivos, 2006).

Building trusting family-educator relationships in spite of systemic inequity is a difficult but vital task in the movement for educational justice. General advice abounds regarding how educators can engage families in ways that increase trust and connection. For example, scholars recommend that educators communicate openly, demonstrate that they care, create a welcoming environment, conduct home visits, make positive calls home, take family concerns seriously, and treat people as individuals (i.e., resist stereotypes; e.g., Brewster \& Railsback, 2003; Epstein et al., 2018). This work, however, often underappreciates the extent to which systems and histories related to race and power shape cross-racial and -cultural relationships and must be addressed in the relationship-building process (Gallo, 2017; Park \& Paulick, 2021). In response, Vakil, de Royston, Nasir, and Kirshner (2016) seek to expand our definition of trust to include what they call political trust. Speaking from the context of design research in education, the authors argue that trust building within cross-racial collaboration requires a form of "political or racial solidarity" (p. 199) rooted in an explicit recognition of historical and current power relationships.

Neither trust nor solidarity is gained (nor should it be) by the assertion of good intentions, nor is it accomplished merely once and then set aside. Instead, politicized trust calls for ongoing building and cultivation of mutual trust and racial solidarity. It is thus a trust that actively acknowledges the racialized tensions and power dynamics inherent in design partnerships. (p. 199)

Building on the concepts of relational and political trust - and the recognition that building, rebuilding, and maintaining trust is an ongoing process of small interactions that, over time, reinforce or disintegrate family-educator relationships (Lawrence-Lightfoot, 2003; Vakil, de Royston, Nasir, \& Kirshner, 2016) — this article fulfills a pressing need for critical research that examines relationship

building at the micro level and seeks how we can successfully create spaces for trust-building interactions to flourish.

\section{Our Research Project}

This study is part of a community-campus partnership called the FSC Design Research Project, which 
is led by an evolving team of academic researchers, parent leaders, organizers, educators, and graduate students. Partners for the project include the University of Utah College of Education, the Utah Community Advocate Network (UCAN), the Salt Lake City School District, and University Neighborhood Partners, a department that convenes and supports community-campus partnerships on Salt Lake City's west side. As members have transferred to new universities but remained with the project, we have also developed connections at Michigan State University and the University of Nebraska, Lincoln.

The FSC Design Research Project is part of the Family Leadership Design Collaborative (FLDC), a national network based at the University of Washington School of Education. The FLDC utilizes a research methodology we call solidarity-driven codesign, a critical and participatory form of design research (Bang \& Vossoughi, 2016). Design research in education aims to advance educational theory and practice by enacting, studying, and revising educational theories and interventions amid the messiness of real-life learning situations (Cobb, Confrey, diSessa, Lehrer, \& Schauble, 2003; Collins, Joseph, \& Bielaczyc, 2004). Solidarity-driven codesign both extends and challenges previous design research processes by employing critical, decolonizing, and community-based methods (Beckman \& Long, 2016; Smith, 1999; Strand, Cutforth, Stoecker, Marullo, \& Donohue, 2003). Furthermore, solidaritydriven codesign centers upon the knowledge and participation of families from nondominant communities and provides ongoing attention to questions of power and inequity, not only in terms of the topics of study but also among codesigners themselves. As Bang and Vossoughi (2016) explain, this approach "links both structural critiques of normative hierarchies of power and imagined possible futures" while concurrently being "committed to consequential impacts in the here and now" (p. 174).

Solidarity-driven codesign follows an iterative 4-step cycle (Family Leadership Design Collaborative, 2019). It begins with relationship building and theorizing, during which diverse stakeholders engage in storytelling and assuming another person's perspective while working to create an inclusive space that attends to interpersonal power dynamics. Next, in the design and development phase, participants engage in multimodal activities to develop potential solutions to educational injustices that are rooted in the expertise and practices of nondominant families. In the third phase enacting - participants pilot their designs in a real-world setting and collect data that aid understanding of the design's process and impact. Finally, in the analyze-and-reflect phase, the group collectively assesses the work, shares learning, celebrates successes, and utilizes new knowledge to launch another cycle of redesign. In reality, these phases are not clearly delineated, and some steps such as relationship building - are ongoing throughout the design process. In this article, we examine data from the period before we enacted our pilot designs; therefore, the data focus mainly on Phases 1 and 2 of the cycle.

Our project centered around SCCs, a form of family involvement in school decision-making. SCCs are mandatory at every school in Utah and exert control of discretionary funds derived from profits on Utah lands that are held in trust for schools (School Land Trust Program, n.d.). SCCs comprise an administrator, at least two school staff, and at least four parents or guardians; parents must outnumber staff by at least two. SCCs are tasked with reviewing, revising, and approving a school improvement plan and creating a proposal to utilize the aforementioned state funds.

For years, parent leaders and community-minded educators had lamented that SCCs were failing families in the city's west-side neighborhoods, which are home to the majority of the city's residents of color as well as residents of immigrant, migrant, and refugee backgrounds, including $75 \%$ of the city's Spanish-speaking population. The west side has faced a history of disinvestment, marginalization, and educational inequity, as it is separated physically and culturally from the wealthier, Whiter east side (Downen, Perlich, Wood, \& Munro, 2012). SCCs in west-side schools had typically 
recruited and retained low numbers of students' family members or only White families, and families who attended often reported feeling that they were rubber-stamping plans created by educators.

The question for our project became this: how can we reimagine SCCs so that they are spaces for equitable parent leadership and FSC? This question led to the design of multiple products that were later piloted in schools, including a comic book that parents could utilize to recruit other parents to SCCs and educate families regarding their rights. However, in this article, we focus not on the products of the design circles but on the process. In this way, we aim to ascertain the possibilities illuminated by this process for building equitable family-educator relationships.

\section{Research Methods}

Our project utilized design circles (Ishimaru, Rajendran, Nolan, \& Bang, 2018), in which community members gathered to codesign theories of change and solutions to pressing community issues. Design circles are similar to traditional focus groups, as they convene people from the study context in a recorded conversation who share their thoughts and experiences. However, in a design circle, sharing stories is one step in a larger process that includes relationship building, collective analysis of one another's stories, discussions of larger sociopolitical structures, and the cocreation of theories and solutions. Ishimaru and Bang (2016) describe circles more accurately as "in-depth reciprocal working groups"(p. 14) that leverage multiple forms of knowledge to catalyze action. Design circles are generally not singular events; rather, they are conducted in a series with time between each meeting during which facilitators investigate data from the previous circle and utilize them to inform the next by analyzing the flow of the conversation, determining ways to improve facilitation, and identifying data to present to the larger group for collective discussion.

We organized three design circles over the course of a month; each was 2.5 hours in duration. All meetings were audio recorded and transcribed for analysis. We sought to create a space that was welcoming and accessible to both educators and families while specifically focusing on addressing the barriers that often exclude CLD families from school activities. We held the sessions at a community learning center that was frequently utilized by and comfortable for many families. We provided meals and childcare at all sessions and engaged in Spanish-English and English-Spanish translations throughout.

We invited approximately 10 parents of public school children. All but one were Spanish-speaking parents with immigrant backgrounds from Mexico and other Latin American countries; the remaining parent was a Somali American of refugee background. This reflects the primarily Latinx or Hispanic makeup of our main partner, UCAN, which is an intergenerational group of family and community leaders. Latinx or Hispanic students comprise $38.7 \%$ of the district's enrollment and are the majority in most west-side schools (Salt Lake City School District, 2021. We also invited approximately 10 educators in a range of positions - principal, assistant principal, counselor, teacher, family advocate, and district leader - all of whom had some experience in overseeing family engagement activities at the classroom, school, or district level. ${ }^{1}$ Two of these educators, both of whom were in positions related to FSC, were Latina. The rest were White non-Latinx or Hispanic. The specific concern with SCCs that drove our effort originally emerged from conversations with UCAN and many of these educators. Several of these parents and educators were from the same schools, and some were already acquainted. Parent participants received a small stipend to honor their volunteered time.

Four of us comprised the lead research team for the design circles: Gerardo López, then a faculty member at the University of Utah College of Education; Almaid Yanagui, a local parent turned community organizer; Jennifer Mayer-Glenn, director of FSC for the school district; and Paul Kuttner, a community engagement professional from the University of Utah. Anne Barton, a graduate student, joined in a later phase of the project and supported analysis for this article. Our team met several times over the course of 4 months to discuss the objectives, goals, and facilitation techniques for each design 
circle. With no firmly-established facilitation method for solidarity-driven codesign, we employed our backgrounds in teaching, meeting facilitation, and community organizing to lead discussions in a way that we thought would be culturally familiar and inclusive in our specific context. As demonstrated in the data sections that follow, we utilized tools such as small group discussions, circle practices in which each person receives dedicated time to speak, engagement opportunities in English and Spanish, and parent or educator affinity groups. We conducted a range of activities that included storytelling, presenting, analyzing quotes from previous circles, and drawing collectively. Almaida and Gerardo were lead facilitators for the design circles. The following were the overarching goals of each circle.

Design Circle 1: Discuss the topic of home, school, and family relationships from a critical perspective (i.e., What does it mean? Why do we do it? What do we hope it can accomplish?). Participants are asked to identify the challenges in home, school, and family relationships from their respective positions or vantage points.

Design Circle 2: Provide participants with information regarding the history and structure of SCCs and invite them to probe deeper into the specific challenges they face in orchestrating successful SCCs at their schools.

Design Circle 3: Engage participants in a redesigning process by posing the following questions: How can we rethink the SCC? In other words, what should a healthy and functioning SCC look like? What should it feel like? Who comes to the table?

\section{Analysis}

The findings in this article are based on a qualitative analysis of transcripts from the three design circles. We began by reading each transcript multiple times and discussing our observations while comparing the transcripts with our impressions as facilitators and participants in the circles. We then returned to the transcripts with a grounded coding process (Charmaz, 2007; Saldaña, 2015) to identify moments in which families and educators interacted in ways that offered promise for building equitable, trusting relationships. We sought segments of the transcripts that evinced the components of trusting relationships: empathy, listening, understanding, vulnerability, honesty, and humility, such as occasions when participants shifted from unidirectional interactions (e.g., telling, convincing, and explaining) to bi- and multidirectional interactions (e.g., asking and learning). These moments of connection were occasions when participants truly and deeply related with one another despite the personal, historical, social, and institutional forces that so often hinder this kind of relationship. We developed codes inductively to name the different types of connections (e.g., empathy or building on others' ideas).

By focusing our analysis on moments of connection, we sought what Lawrence-Lightfoot and Davis (1997) call goodness. We were less interested in discovering evidence of pathology and challenge than in determining possibilities and solutions. However, similar to Lawrence-Lightfoot and Davis, we understand that goodness is laced with imperfection. Consequently, in addition to coding for moments of connection, we coded the conversations around those moments, seeking what appeared to lead to or support these moments and what appeared to hinder or obstruct these moments. This led to another set of inductive codes that were focused on key topics or issues that sparked moments of connection and disconnection. We then employed coded sections and, through an iterative process of discussion and writing, merged and synthesized them into a set of themes that answered our questions (Saldaña, 2015). The importance of building trust was predominant from the beginning to us as facilitators and researchers; however, the salience of relational and political trust specifically emerged inductively as a strong through line across themes.

We, the five aforementioned authors, conducted the analysis for this article. We did not aim to incorporate the larger group's participation in the project, and we recognize that they may have 
different perceptions of the data we present. We could have learned much from gathering the participants of the design circle once more to reflect on data and experiences from the first three circles. Interesting tensions are produced from the question regarding the appropriate amount of participation when creating academic products from solidarity-driven codesign. Should everyone be involved in every publication or presentation to acquire the richest and most multivocal analysis? What if, as with our case, community members are more interested in spending their limited time advancing the transformative work in schools rather than speaking to an academic audience? Solidarity-driven codesign leaves room for multiple approaches, and the specifics likely need to be negotiated within each project.

Concurrently, our approach breaks with traditional extractive research approaches in two ways. First, our core facilitation and research team was designed to include members of the key communities involved - a district educator and a local parent or organizer. Three of our five authors are Latinx, and the other two are White, non-Latinx. While we cannot speak for the larger communities of which we are a part, we bring a diverse array of positionalities, experiences, and ways of making sense of the world. Our small group reflects some of the same dynamics we witnessed in the circles. Moreover, during each design circle, we asked the larger group to reflect on the previous circle, and occasionally, we analyzed prior circle transcripts together. This is markedly different from traditional focus groups in which participant contributions are considered raw data to be analyzed by researchers at a later point. Therefore, our conclusions have inevitably been shaped by the critical thinking and analyses of our participants, and we are indebted to them for this knowledge.

The analysis in this article is perhaps optimally understood as a structured way for us as facilitators to critically reflect on our facilitation process. Such reflection, we have found, is critical to solidaritydriven codesign. Similar to the codesign process itself, facilitators must experiment, reflect, and improve the design of the spaces in which design occurs, with attention to racialized and other power dynamics that assert themselves in the process. As we explain in our discussion, these findings are tentative and exploratory but suggest avenues for further action and research.

\section{Findings}

In the following sections, we closely examine moments of connection between families and professional educators during our design circles, with particular attention to how they relate to the building blocks of relational and political trust.

\section{From Vulnerability and Reflectivity to Empathy}

The overarching goal of the first design circle, as Gerardo explained to the group, was "to really interrogate the promises and the challenges of school-community relations." Accordingly, we split the group into two self-identified smaller groups comprised of families and professional educators. Each was asked to identify, from their perspective, the key challenges to collaboration. When they finished, representatives from each group presented the list of challenges (without identifying any comment's contributor), and the other group was asked to reflect on the presentation. We designed the discussion this way to create space for people to express their frustrations and negative experiences with a reduced level of personal risk. We believed that this structure would allow people to raise critiques that may be silenced if we began the discussion as a large group and people had to own each critique individually. We were also intentional in framing the groups' presentations as a time for listening and acknowledging one another's experiences rather than defending or explaining them.

Some of the most promising moments of connection began in the first design circle when the educator group, who volunteered to present first, delivered their challenges and, in the process, 
expressed vulnerability and reflectivity. In their presentation, educators stressed the drawbacks of teachers not living in the neighborhoods in which they teach. They said that teachers must be more culturally responsive and leave the school campus to become acquainted with the community. Perhaps more importantly, they expressed personal fears. Reading their list of challenges, the presenter ended with, "There's a lot of fear about things we engage in... opening our buildings to the community in current climate of violence...Fear, fear that I'll step on toes. That there will not be a payoff." Educators described the difficulty they feel when changing their methods of interactions with families. "How do I break out of my ways? Time and tradition. Change is hard. The only reality you know is what you are raised with. How do you think differently together?"

In response, some of the parents noted the honesty and vulnerability in the educators' comments. One parent said, "I hear some honesty in there. There's a lot of acceptance right there. There is a lot of willingness of making a change." Another parent highlighted the topic of fear, saying, "I hear that they have a fear of failure probably to the parents as a community too." This led still a third parent to call for empathy:

It's very easy to point to a teacher. But you're not in their shoes. They have families, they want to study, go back to school. I think it will be a better community if we put on their shoes. And understand better. They in ours, and ours in theirs. Both of us.

This refrain of "putting on their shoes" was emphasized by other participants when the parents presented their challenges. They offered a critique of what they perceived as unwelcoming and unhelpful attitudes in schools. Concurrently, they recognized the complex humanity of school staff.

[Another challenge is] trust, because sometimes, the people [at the school] are not willing to help us. I don't know. They're not in a good mood sometimes. Like you said, put on their shoes. They put on our shoes. We know as parents, too, that they have a life, like she said. Maybe that they cannot be having the best day of their life, but they're working there.

The parents further described a series of concerns that implicated educators. They expressed worry that some educators were merely completing tasks rather than participating in the community, loving their work, and passing that love to the students. Parents additionally stated that teachers disciplined students without inquiring regarding circumstances in the child's life that may be impacting them. Concurrently, they drew parallels between parents and teachers, noting that teachers also face challenges. In response, one educator honored the parent's honesty with another empathetic reference to the metaphor of shoes. In this case, the educator was a Latina family liaison with neighborhood roots who was both school staff and a community advocate:

What I hear as one of the educators is [that] this is an invitation. As parents, you are inviting us to understand what you want to understand. Because I think, sometimes, we may all speak English at some point, but we don't make sense to each other. We want the same thing...It's inviting us to be in your shoes.

By presenting fears, difficulties, and potential improvements, the educators engaged in several facets of trust that are commonly presented in the literature, including openness, honesty, and vulnerability (Tschannen-Moran \& Hoy, 2000). Parents, in turn, expressed empathy and a recognition of educators as full people with challenges and lives outside of their school-based interactions. Moreover, participants capitalized on the session's structure to listen and engage with one another's concerns, which communicates respect (Bryk \& Schneider, 2003). This established a strong foundation for dialogue and a potential foundation for solidarity and action.

\section{Shared Frustration and Alienation}

Other moments of connection emerged from shared experiences of frustration with the school system. Both groups communicated their frustrations and, with the facilitator's support, framed these 
as a point of connection. During the first design circle, parents expressed frustration with schools that asked them to rubber-stamp plans that they did not create and often did not have time to understand. As one parent shared, "You just throw the paper [and say] "please sign it." Families expressed frustration with schools that failed to understand, recognize, and validate their educational concerns or the complexity of their lived realities. Educators, in turn, expressed frustration with district policies that discourage connection with the community and support deficit assumptions about families. As one stated,

We spent a good amount of time talking about how we have barriers in our policy and in our attitudes about making home visits, about going to people's homes. That in the policy in our district, it says that you cannot do home visit[s] unless you go with someone else. You can't go alone. Part of what that policy makes people think is fear. It makes us feel fearful. There must be reasons why we can't go on this visit because that means that there must be something dangerous in the homes or something like that. Our own policies make it harder for us as educators to interact.

Educators further noted the considerable demands on teacher and parent time in schools as well as the perception of educators as being part of the establishment and thus untrustworthy. In other words, both groups expressed frustration with the structures and processes that shape family-school relations.

While these frustrations often targeted different sources (e.g., district policies vs. school-level practices), common ground appeared. One teacher spoke to the similarities between his frustrations and those of parents, highlighting systemic issues that affect everyone in schools and seeing himself in the experiences of families:

As a rank-and-file teacher, those are my frustrations, too. I'm part of a system. My principal, when he tells the budget, I have no say in that. He's just informing me, "Here's the budget. Deal with it." I could easily have written that [the parents' list of challenges] as a classroom teacher.

Gerardo reiterated this idea of frustration as a shared and systemic experience when summarizing remarks at the end of the first design circle. He framed it as an experience of mutual alienation. He noted, "It's fascinating just to see how both sides are dealing with forms of alienation. How we're collectively being alienated from each other." Gerardo reintroduced this idea to begin the second design circle, and as the group reflected on their previous discussion, the Latina family liaison seconded it: "I can see that policy kind of prevents us from being involved with each other."

During the second design circle, the group heard a state-sponsored presentation regarding the workings of SCCs, which raised new frustrations among parents, educators, research staff, and even the presenter herself. For example, participants expressed dissatisfaction regarding the lack of translated documents and the narrow limits for utilizing SCC funds. The presenter affirmed these challenges while also expressing exasperation that she could alter nothing without legislative change. The language of alienation was further emphasized by two educators and the presenter to describe the impact of SCC processes, such as distributing untranslated or difficult-to-understand documents, voting for SCC members, and comprehending rules regarding council eligibility.

Feelings of irritation and powerlessness culminated with a particularly vulnerable comment from one of the administrators. Gerardo utilized this as another moment to note his perception of common feelings around the room:

Administrator: I'm going into my third year as principal, and my School Community Council is something that I feel like I have completely failed at. As a human, it sucks to fail. I know it's important, but I feel like other community work that we're doing, it matters.... when it comes to School Community Council, and all of the work we've tried to make it work in our school, it ends up feeling like compliance, and no one likes compliance because the focus is lost. I think we all learned today. We understand that there's a good purpose behind it, but it gets lost in all the bureaucracy. It doesn't feel like meaningful work. It feels like something that is on my list that I hate and that I don't do well 


\section{Building Equitable Relationships}

at. How do we make that meaningful? I don't know because I feel like there's so many barriers. That's my frustration. I understand the purpose behind all of it, but, on the ground in my school, it doesn't look like that. It doesn't make sense. I don't know how to wrap my head around it and how to feel successful at it. I'm hoping that something will come of this.

Gerardo López: I think what I'm sensing from your comments is that sense of frustration, that sense of, this is something that we are required to do, and it hasn't worked out. I'm also hearing the same kind of message from the parents as well.

Administrator: Exactly. It's failing for all of us, and it doesn't feel successful to my community. I don't know how to do it. I don't.

The facilitator's move to frame participants' frustrations as shared experiences of alienation created by the school system enabled some of the educators to see potential for solidarity with families, which is a central facet of politicized trust (Vakil, de Royston, Nasir, \& Kirshner, 2016). The participating parents were less involved in this discussion — possibly because we arranged the second design circle in a way that was alienating for the parents, and this action afforded a privilege to the educators (i.e., the formal presentation with a large group discussion focused on the technicalities of educational policy). Additionally, the lack of parental input in this conversation may have been because the effort for participating parents to equate the two experiences with the school system did not fully resonate. We explore this in the next section.

\section{Money and Value}

Both parents and educators in our group expressed negative impacts from the school system. However, they were not affected equally. Families and professional educators hold different positions within the schools' power structures as well as within the racialized and economic hierarchies of society. The parents in our circle understood that they were in a more marginalized position than the educators.

One parent acknowledged this inequity during the parent-only small group in the first design circle, as he responded to another parent who commented that teacher pay was low: "Teachers are making $\$ 25$ an hour. I'm making 10. Is it low? No, it's not low. In comparison to mine, it's not low. In comparison to the superintendent, yes." This parent questioned the common narrative that teachers are not paid what they deserve by clarifying that low teacher pay is relative. In other words, he highlighted the fact that this common discourse ignores the financial hierarchy between families and schools in communities such as west Salt Lake City.

The idea that teachers are paid insufficiently suggests that they are not paid according to their full value. What does it mean, then, that many parents are paid less than teachers yet are still asked to volunteer their time in the school? As the same parent said,

I have come to meetings where I'm participating as a volunteer. I sometimes would get a mere thank you when I know that the teacher was paid to be in the meeting. He stayed for 2 hours; he gets his 25 bucks an hour. That will make some of us not want to participate, because...I have to take away 2 hours of my time from where I work making $\$ 10$ an hour. For me, it's $\$ 20$ only, 2 hours, and then I'm going to sit right there and the teacher is making $\$ 50$.

Another parent opined that money was not the issue as much as valuing and honoring people's contributions. She said, "We're not asking [for] incentives either from the school. We just want to make [you] recognize that we were there and that you know that we were there to help...A simple thank you."

In their presentation, parents shared these concerns with the educators. When educators reflected on parents' statements from the first design circle, one administrator - a Latina with a long history in the community — addressed the comments regarding pay: "One thing that I heard loud and clear 
was that teachers complain about not being paid enough, but teachers actually get paid a lot more than people in the community." By honoring this comment (rather than, for example, becoming defensive), the administrator communicated her agreement and desire to address the issue in the design process. In the final design, recommendations included both financial remuneration for parents as well as other ways of honoring their engagement through food, celebrations, and awards.

This discussion suggests that cross-racial solidarity requires more than sharing frustrations or goals. In line with Vakil, de Royston, Nasir, and Kirshner's (2016) argument, it demands explicit contention with systemic power imbalances, both racial and otherwise, that affect families and educators differently. In this case, raising these issues created an opportunity for educators to hear, honor, and consider family critiques, which could deepen the sense of mutual respect (Bryk \& Schneider, 2003).

\section{Building on Ideas and Learning}

One opportunity that the design process afforded participants, which many family-school interactions do not, is the ability to create together. In the third design circle, we asked small groups of parents and educators to reimagine SCCs. Gerardo explained it this way:

If we had an opportunity to redesign this, to rethink this, to create something that would work, what would a functioning SCC look like for you? What would that look like? What would it feel like? What would it taste like? I said it tastes like tamales. That's what it would taste like, but that's me.

Each group received paper, markers, and an open license to create in whatever form they wanted (e.g., visual art, sketches, text). Facilitators visited tables to nudge the conversations forward and elicit engagement from quieter participants.

This process unlocked opportunities for another kind of connection - building on one another's ideas. One example is the following exchange between a parent (Latina), a counselor (White female), and an administrator (White male):

Parent: I feel that sometimes the reunions [meetings] need to be more like family reunions. Like he said, maybe with food from different countries, and they can speak about their own countries. Before they start talking about academic issues or, I don't know, economic. We need to know each other: What's your name? Where do you live? What are your issues? A little more like a family reunion - first to have empathy, to feel that you are part of something.

Counselor: Yeah.

Parent: You need to do something, like about empathy, feelings, something like that. It may be a Latin way, but I think this would work. I have [a community organization, and in the name is the word] casa. I put casa because with the name, they can feel like, "Oh, casa." It's something that attracts them, and I think that this is the first thing. By then I'll start having empathy, no issue.

Counselor: What I'm hearing you saying is before we even start the SCC, meaning that [at] the beginning of the year, we have those parents there, and it's got to be a fiesta or a party itself. To get together, to know each other, even if it's a small group, because that's where we're going to build relationships and trust, and then we can move on with the business of the school at hand.

Administrator: With this, and this is a pretty basic question, where I grew up, we would always have a potluck or something like that, where everyone brings a dish and you share. Is that something appropriate to ask?

Parent: Yes, that would be your second meeting.

The parent employed her cultural and professional knowledge to reimagine the SCCs. The educators encouraged her to continue, demonstrated that they were listening, and then connected the ideas to their own lives. The counselor built on the idea of a family reunion with the idea of a party, although that arguably misses the family association that the parent suggested. She also utilized the 
Spanish word fiesta, perhaps to connect with a Spanish-speaking parent or perhaps to build on the parent's usage of casa as a culturally relevant concept. Meanwhile, the administrator inquired whether it would be appropriate to ask parents to bring food, and the participating parent resisted, saying essentially that the school should be responsible for the initial event. Ultimately, both ideas - a more family-like or homelike space and school-planned fiestas to begin the year — were included as proposals in the final report. This process of listening respectfully, honoring each other's knowledge and expertise, asking questions to learn, and persisting by including those ideas in the final product implements many of the building blocks of trusting, equitable relationships.

Building on one another's ideas demonstrates respect for the other person as well as appreciation for their competency (Bryk \& Schneider, 2003). In this case, educators acknowledged a parent's competency not only as a parent but also a community leader and a cultural authority. This concept of a parent role is broader than traditional in family engagement and celebrates the knowledge that CLD families provide (González, Moll, \& Amanti, 2006).

\section{Discussion}

In the previous sections, we shared moments of connection that occurred during our participatory design research project as well as encouragements or hindrances to these moments. As schools and families are increasingly asked to collaborate to support student success, these moments suggest promise for building the trusting relationships needed to undergird such collaboration. These findings are preliminary; we cannot say that the dynamics of our group will necessarily translate to others. Our group had a particular makeup: mostly White educators and Latinx families of immigrant or migrant backgrounds, the majority of whom had experience in FSC. Concurrently, we perceive clear connections to existing literature and the potential that our findings may resonate with other contexts.

Our research suggests that possibilities for building trust are opened when educators express vulnerability and self-critique to families. This is not common in our school system. More often, families are expected to be vulnerable — disclosing home events, accepting advice regarding their children, or allowing teachers to conduct home visits. Generally, teachers are not asked to be equally vulnerable regarding their fears and mistakes; rather, they are expected to project confident professionalism. Many teachers express fear of parental judgment, especially when parents ask to visit their classrooms (Hong, 2011; Lawrence-Lightfoot, 2003). However, our research suggests that overcoming that fear and allowing vulnerability to surface can humanize teachers in parents' eyes. Families may respond with empathy.

These findings further suggest that shared frustration with the educational system creates potential for solidarity between families and educators. Families are often exasperated with the educational system, especially nondominant families who face layers of marginalization in schools. As the educators in our study noted, teachers and administrators are often the face of that system and thus receive the brunt of that frustration. However, educators are also impacted by the system in which they work, often in negative and dehumanizing ways (Carter Andrews, Bartell, \& Richmond, 2016). Sharing those irritations with families and listening nondefensively to families' frustrations opens avenues of understanding and common causes. To utilize the language of our circles, the school system alienates families and educators from one another, but collaborative critique of an alienating system can be a point of connection.

However, this strategy of sharing alienation or frustration can backfire. Educators and families are not equally impacted by the school system, particularly in low-wealth communities of color with a majority of White, middle-class teaching staffs. Simply stating, "We're all in this together" without recognizing the power differentials between families and schools could lead to resentment and distrust. 
Concurrently, enabling critiques of these differential positionalities can advance the conversation and, eventually perhaps, strengthen trust by attending to its racialized and political aspects (Vakil, de Royston, Nasir, \& Kirshner, 2016).

Additionally, our research suggests the value of families and educators engaging in cocreation, sharing knowledge, and building on one another's ideas. A significant line of research highlights families' knowledge and assets and ways to introduce these aspects to school spaces to improve education (González, Moll, \& Amanti, 2006; López, 2001; López \& Vàzquez, 2006). However, deficit views of parents continue to proliferate in our school systems (Olivos, 2016). Educators need opportunities to experience firsthand the assets that families provide. In our case, codesign offered a critical scaffolding for this process, and we see significant potential in spreading the usage of this research approach in education.

Notably, the two Latina educators in the room, working in positions focused on FSC, were essential members in some of the interactions outlined above. At key moments, these individuals highlighted and validated parent critiques from an educator perspective. This emphasizes the value of cultural brokers - individuals who can bridge and mediate between the cultures, languages, and perspectives of families and schools (Lopez \& Stack, 2001). Cultural brokering is a complex process that can be utilized as a further tool for socializing parents into dominant school cultures; however, it also offers potential for sparking additional transformative relationships (Ishimaru et al., 2016).

Finally, we cannot separate moments of connection from the fact that this was a highly designed and facilitated space. Our choices as a planning team were critical to the interactions that occurred. These decisions included whom to invite, where to hold the circles, what to include on the agenda, where people should sit, how discussions would be held (e.g., affinity groups, small groups, or the whole group), which topics or data would continue from one session to another, how many sessions to have, what ideas facilitators should highlight, and much more. For example, more than one reviewer of this article has remarked on the rarity of educators being as vulnerable as they were and questioned how it was possible in this context. While we cannot know with certainty, our prior design and facilitation choices likely had a substantial impact: we had prior relationships with each educator in the room; we invited educators who commonly expressed critiques of racist practices in schools; we invited parents from across the district, so educators were not speaking primarily to families from their own schools; and we had educators initially meet in the relatively safe space of an all-educator group before presenting together. After every session, our team reflected and redesigned, learning from our facilitation mistakes as well as our successes. While no one way is perfect to facilitate family-school relationship building, we believe that these design questions must be addressed thoughtfully.

\section{Implications and Conclusion}

The importance of relationships in FSC cannot be overstated. Understanding family-educator dynamics, particularly within inequity and power imbalances, is critical if we are to consciously foster such relationships in our schools and communities. The findings in this article, although tentative and exploratory, suggest avenues of possibilities for this relational work that is relevant to scholars and educators.

Primarily, this research communicates the possibilities and challenges of codesign work between families and educators. An emerging field of research and practice, codesign efforts may offer a vital alternative to school-centric, educator-dominated family engagement approaches (Ishimaru, 2019b). Our study supports this claim and offers recommendations for structuring and facilitating the design process to support family-educator relationship building. For example, it highlights the importance of engaging in self-reflection, of creating low-risk opportunities to express vulnerabilities and critiques, of implementing structured time to listen reflectively, of facilitating critical analysis of systems that 
honor all experiences while also recognizing asymmetrical power relationships, of including cultural brokers in the group, and of unlocking space for creativity and imagination. Furthermore, it emphasizes the importance of presenting multiple opportunities to engage over time. The collaboration and respect we witnessed at the third session would likely not have been possible at the first or even the second meeting, because the ability to include these elements relied on participants feeling sufficiently safe and trusting to honestly share their ideas.

A more challenging question, perhaps, is how educators can foster these types of interactions within existing school and community spaces, where they have less control over the who, what, when, and how of engagement. On the one hand, educators can rethink how they employ existing interactions. Where can vulnerability be expressed? Are they responding to families' issues with affirmation and understanding of systemic injustice, rather than being defensive or dismissive? Could parent-teacher conferences be an opportunity to build on one another's ideas rather than a one-way information session? On the other hand, our traditional structures of family-educator interactions are typically school-centric and fraught with power imbalances and settled scripts. Our findings stress the importance of educators leaving their classrooms and offices to create new opportunities to interact and to work with families and community partners to build new spaces that bridge community and school.

Ultimately, we see the potential of these family-educator interactions to create more than simply trust, although this factor is critically important. These moments of connection further offer the possibility of a more humanizing form of family engagement. According to Gallo (2017), bumanizing family engagement challenges deficit narratives regarding bicultural families and families of color, fosters understanding of people's diverse lives and challenges, honors and builds on the assets and knowledge of all parties, and involves critical introspection. Humanizing engagement is a long, slow process built through humanizing interactions among educators, families, and students. While far from perfect, our design circles appear to have fostered humanizing interactions: these moments enabled families and educators to look past assumptions and biases, seeing one another as full people with complex histories, lives, and futures and appreciating each other's valuable professional and cultural knowledge. This sense of connecting on a human level was captured in one parent's reflections a year later: "Design Circles was well thought out. Even the before and after social conversations that took place gave me a sense of belonging. I felt I was at the right place with the right people at the right time." We are not arguing that a few positive interactions will transform family-school relationships. Rather, we are suggesting that viewing these interactions as small openings or cracks in the barriers between families and schools - noticing, appreciating, and seeking to create more of these connections can reveal new pathways to allow humanizing relationships to thrive.

In this project, one of our ultimate goals was to shift power imbalances that subordinate CLD parents to educators and alienate them from decision-making power within the school system. Relationships, regardless of their strength, do not automatically change power dynamics. However, we understand them to be an indispensable part of the process of shifting power in schools. Only when educators and families have mutual respect and willingness to be vulnerable can they undertake the risks associated with sharing power. Only when families and educators build racial and political solidarity can they begin to address the root causes of power imbalances. We have only begun to create SCCs that are truly hubs of family power in schools; regardless, we have observed ongoing shifts in power relationships throughout our project. For example, during our pilot, we were thrilled to see school administrators and teachers lending their support to a parent-led effort to recruit families to the SCC and educate them regarding their rights. Moreover, these educators accepted families from outside their school communities into the SCC as coresearchers who observed and took field notes on the councils' workings, which are roles that parents are rarely permitted to fill within schools. 


\section{Journal of Family Diversity in Education}

At the end of the third circle, Almaida offered a tearful closing speech to the group, emphasizing the rarity of this kind of opportunity:

I wanted to share one thing with you guys...For the past 12 years, I've worked with families in the community, and time and again, I would come to administrators or come to this group of people that wanted to make a change in the community, and I would say, "Well, we need to bring groups together. We need to bring parents, teachers, and administrators together; we need to talk this out." And they said, it could not be done. But you are history in the making. It was able to be done. We did it here. We came together, we talked about a topic that affects everyone, that affects our children, that affects the education that our children are receiving, and our voices were heard all around the table. When they said it could not be done, we did it. Thank you. Give yourself a hand.

This project was largely uncharted territory for every person in the room, including us. Nothing like this has previously happened in our district, and so we began with a sense of hope and experimentation as well as naivete regarding the potential challenges. For example, we underestimated the extent to which unequal power relationships would assert themselves during discussions or how explicit we would need to be about centering on families and facilitating discussions regarding inequity and racism.

Our approach evolved over time as the project entered new phases. We have enjoyed success with family-only and family-dominated design circles, which created additional room for CLD parents to assume the lead in the design process and outcome. We struggled when we made the circles excessively large with people who did not have existing relationships and when we broadened our focus to FSC in general. We engaged in difficult conversations about intersectional power when gender and racial or ethnic dynamics in the group combined in complex ways to make equitable discussion difficult. Moreover, COVID-19 pushed us to radically reframe our process, and our study evolved into a Zoombased video project in which experiences of families and educators were shared. As with familyeducator relationships, the work of solidarity-driven codesign is not a static concept with a clear end. This ongoing and evolving process needs constant attention, learning, and work as the people and the context change. We hope this research contributes to the never-ending, rewarding work of building humanizing family-school relationships.

\section{Notes}

1. We invited an equal number of parents and educators with the idea that this would create a context in which both groups felt that they were on equal footing and felt safe to talk without dominating. However, we later recognized that numerical equality may not actually be effective in creating the equitable relationships that we need in the long term. In fact, SCCs call for more parents than educators in their membership. Over the years, we have increasingly shifted to inviting fewer educators than families to ensure that family perspectives and leadership are the core.

\section{References}

Adams, K. S., \& Christenson, S. L. (1998). Differences in parent and teacher trust levels: Implications for creating collaborative family-school relationships. Special Services in the Schools, 14(1-2), 1-22.

Adams, K. S., \& Christenson, S. L. (2000). Trust and the family-school relationship examination of parentteacher differences in elementary and secondary grades. Journal of School Psychology, 38(5), 477-497.

Anderson, G. L. (1998). Toward authentic participation: Deconstructing the discourses of participatory reforms in education. American Educational Research Journal, 35(4), 571-603. 


\section{Building Equitable Relationships}

Bang, M., \& Vossoughi, S. (2016). Participatory design research and educational justice: Studying learning and relations within social change making. Cognition and Instruction, 34(3), 173-193.

Beckman, M., \& Long, J. F. (2016). Community-based research: Teaching for community impact. Sterling, VA: Stylus Publishing, LLC.

Brewster, C., \& Railsback, J. (2003). Building trusting relationships for school improvement: Implications for principals and teachers. Portland, OR: Northwest Regional Educational Lab.

Brown, F., \& Hunter, R. C. (1998). School-based management: Involving minority parents in shared decision making. Urban Education, 33(1), 95-122.

Bryk, A. S., \& Schneider, B. (2003). Trust in schools: A core resource for school reform. Educational Leadership, 60(6), 40-45.

Carter Andrews, D. J., Bartell, T., \& Richmond, G. (2016). Teaching in dehumanizing times: The professionalization imperative. Journal of Teacher Education, 67(3), 170-172.

Cartwright, P., \& Noone, L. (2006). Critical imagination: A pedagogy for engaging pre-service teachers in the university classroom. College Quarterly, 9(4), 1-14.

Charmaz, K. (2007). Constructing grounded theory. New York: Sage.

Christenson, S. L., \& Reschly, A. L. (Eds.). (2010). Handbook of school-family partnerships. New York: Routledge.

Clarke, B. L., Sheridan, S. M., \& Woods, K. E. (2010). Elements of healthy family-school relationships. In A. L. Reschly \& S. L. Christenson. (Eds.) Handbook of school-family partnerships (pp. 61-79). New York: Taylor \& Francis.

Cobb, P., Confrey, J., DiSessa, A., Lehrer, R., \& Schauble, L. (2003). Design experiments in educational research. Educational Researcher, 32(1), 9-13.

Collins, A., Joseph, D., \& Bielaczyc, K. (2004). Design research: Theoretical and methodological issues. The Journal of the Learning Sciences, 13(1), 15-42.

Delgado Gaitan, C. (2012). Culture, literacy, and power in family-community-school-relationships. Theory Into Practice, 51(4), 305-311.

Designs for Change. (2002). Chicago's local school councils: What the research says. Chicago, IL: Author.

Downen, J., Perlich, P., Wood, A., \& Munro, S. (2012). Neighborhoods [west side neighborbood profile]. Retrieved from https://partners.utah.edu/about-unp/neighborhoods/

Epstein, J. L., Sanders, M. G., Sheldon, S. B., Simon, B. S., Salinas, K. C., Jansorn, N. R., \& Hutchins, D. J. (2018). School, family, and community partnerships: Your handbook for action. Thousand Oaks, CA: Corwin Press.

Family Leadership Design Collaborative (2019). Transforming the field of family engagement: Co-designing research, practices, and measures for educational justice and community wellbeing. Seattle, WA: Author.

Gallo, S. (2017). Mi padre: Mexican immigrant fathers and their children's education. New York: Teachers College Press.

Greene, M. (2000). Releasing the imagination: Essays on education, the arts, and social change. San Francisco: JosseyBass.

González, N., Moll, L. C., \& Amanti, C. (Eds.). (2006). Funds of knowledge: Theorizing practices in households, communities, and classrooms. London: Routledge.

Henderson, A. T., Mapp, K. L., Johnson, V. R., \& Davies, D. (2007). Beyond the bake sale: The essential guide to family-school partnerships. New York: The New Press.

Hong, S. (2011). A cord of three strands: A new approach to parent engagement in schools. Cambridge, MA: Harvard Education Press.

Hong, S. (2019). Natural allies: Hope and possibility in teacher-family partnerships. Cambridge, MA: Harvard Education Press.

Ishimaru, A. M. (2019a). From family engagement to equitable collaboration. Educational Policy, 33(2), 350385.

Ishimaru, A. M. (2019b). Just schools: Building equitable collaborations with families and communities. New York: Teachers College Press.

Ishimaru, A. M., \& Bang, M. (2016). Toward a transformative research and practice agenda for racial equity in family engagement. Seattle, WA: Family Leadership Design Collaborative. Retrieved from http://familydesigncollab.org/ 
Ishimaru, A. M., Bang, M., Valladares, M. R., Nolan, C. M., Tavares, H., Rajendran, A., \& Chang, K. (2019). Recasting families and communities as co-designers of education in tumultuous times. Boulder, CO: National Education Policy Center.

Ishimaru, A. M., Rajendran, A., Nolan, C. M., \& Bang, M. (2018). Community design circles: Co-designing justice and wellbeing in family-community-research partnerships. Journal of Family Diversity in Education, 3(2), 38-63.

Ishimaru, A. M., Torres, K. E., Salvador, J. E., Lott, J., Williams, D. M. C., \& Tran, C. (2016). Reinforcing deficit, journeying toward equity: Cultural brokering in family engagement initiatives. American Educational Research Journal, 53(4), 850-882.

Khalifa, M. A., Gooden, M. A., \& Davis, J. E. (2016). Culturally responsive school leadership: A synthesis of the literature. Review of Educational Research, 86(4), 1272-1311.

Lawrence-Lightfoot, S. (2003). The essential conversation: What parents and teachers can learn from each other. New York: Ballantine Books.

Lawrence-Lightfoot, S., \& Davis, J. H. (1997). The art and science of portraiture. San Francisco: Jossey-Bass.

Lopez, G. (2001). The value of hard work: Lessons on parent involvement from an (im) migrant household. Harvard educational review, 71(3), 416-438.

Lopez, M. L., Stack, C. (2001). Social capital and the culture of power: Lessons from the field. In Saegert, S. (Ed.), Social capital and poor communities (pp. 31-59). New York, NY: Russell Sage Foundation.

López, G. R., \& Vázquez, V. A. (2006). Parental involvement in Latina/o-impacted schools in the Midwest: Recognizing the role and function of home-based knowledge and practices. Journal of School Public Relations, 27(4), 3-36.

Malen, B. \& Ogawa, R. T. (1988). Professional-patron influence on site-based governance councils: A confounding case study. Educational Evaluation and Policy Analysis, 10(4), 251-270.

Mapp, K. L., Carver, I., \& Lander, J. (2017). Powerful Partnerships: A Teacher's Guide to Engaging Families for Student Success. New York: Scholastic.

Marschall, M. (2006). Parent involvement and educational outcomes for Latino students. Review of Policy Research, 23(5), 1053-1076.

Martell, G. (2008). Why saving a seat is not enough: Aboriginal rights and school community councils in Saskatchewan. First Nations Perspectives, 1(1), 19-40.

Mediratta, K., Shah, S., \& McAlister, S. (2009). Community organizing for stronger schools: Strategies and successes. Cambridge, MA: Harvard Education Press.

Moradi, S., Hussin, S. B., \& Barzegar, N. (2012). School-based management (SBM), opportunity or threat (education systems of Iran). Procedia-Social and Behavioral Sciences, 69, 2143-2150.

DOI:10.1016/j.sbspro.2012.12.179

Nygaard, R. (2010). Sources of Confidence in School Community Councils. School Community Journal, 20(2), 137-158.

Olivos, E. M. (2006). The power of parents: A critical perspective of bicultural parent involvement in public schools. New York: Peter Lang.

Park, S., \& Paulick, J. (2021). An Inquiry into Home Visits as a Practice of Culturally Sustaining Pedagogy in Urban Schools. Urban Education. DOI: 0042085921998416.

Preston, J. (2009). Educational reform via school councils: Comparing Saskatchewan's school community councils to an international precedent. Comparative and International Education, 38(1), 29-44. DOI:10.5206/cie-eci.v38i1.9126

Race Forward. (2006). Historical timeline of public education in the US. Retrieved from https://www.raceforward.org/research/reports/historical-timeline-public-education-us

Saldaña, J. (2015). The coding manual for qualitative researchers. New York: Sage.

Salt Lake City School District. (2021). 2021-2022 Ethnicity Report. Retrieved from https://www.slcschools.org/schools/district-demographics

School Land Trust Program. (n.d.) Brief history of school land trusts in Utah. Retrieved from http://www.schoollandtrust.org/wp-content/uploads/sites/32/2016/02/HISTORY-OFSCHOOL-TRUST-LANDS-IN-UTAH-School-Board-1.pdf

Smith, L. T. (1999). Decolonizing methodologies: Research and indigenous peoples. London: Zed Books Ltd. 


\section{Building Equitable Relationships}

Strand, K. J., Cutforth, N., Stoecker, R., Marullo, S., \& Donohue, P. (2003). Community-based research and higher education: Principles and practices. Hoboken, NJ: John Wiley \& Sons.

Tschannen-Moran, M., \& Hoy, W. K. (2000). A multidisciplinary analysis of the nature, meaning, and measurement of trust. Review of educational research, 70(4), 547-593.

Vakil, S., de Royston, M. M., Suad Nasir, N. I., \& Kirshner, B. (2016). Rethinking race and power in designbased research: Reflections from the field. Cognition and Instruction, 34(3), 194-209.

Warren, M. R., Mapp, K. L., \& the Community Organizing and School Reform Project. (2011). A match on dry grass: Community organizing as a catalyst for school reform. Oxford University Press.

Warren, M., Mapp, K., \& Kuttner, P. J. (2015). From private citizens to public actors: The development of parent leaders through community organizing. In M. Evans \& D. Hiatt-Michael (Eds.), The power of community engagement for educational change. Charlotte, NC: Information Age Publishing.

Yosso, T. J. (2005). Whose culture has capital? A critical race theory discussion of community cultural wealth. Race Ethnicity and Education, 8(1), 69-91. 